\title{
Planteamiento de la dignidad humana desde la teología en perspectiva de interculturalidad*
}

\author{
María Alejandra Alvarado Navarrete**
}

Recibido: 31 de octubre de 2017 • Aprobado: 15 de noviembre de 2017

\section{Resumen}

El trabajo interdisciplinar entre teología, política, estudios culturales y ética, es necesario y útil para el reconocimiento actual de las modificaciones necesarias en el estatuto epistemológico de los derechos humanos. La dignidad, eje central de este conjunto de garantías, supone la puesta al día de caminos de defensa, que aseguren que no se trata sin más de una abstracción, con la que se define a las personas de todas las nacionalidades y culturas. Sino que se trata de la encarnación de realidades cambiantes, pero con rostros concretos. La teología desde la perspectiva de la interculturalidad, se presenta como lugar de reflexión e instancia de crítica de las conservadoras y alienantes maneras de entender y vivir la dignidad desde las esferas política y ética.

Palabras clave: dignidad, derechos, revelación, política, interculturalidad, ética del cuidado.

* Artículo desarrollado como reflexión académica de la Maestría en Teología, período 2017-I, Facultad de Teología, Pontificia Universidad Javeriana. DOI: http://dx.doi.org/10.15332/ s2011-9771.2017.0002.02

** Estudiante de la Maestría en Teología de la Pontificia Universidad Javeriana. Licenciada en Teología y teóloga de la Pontificia Universidad Javeriana. Profesora de medio tiempo de la Universidad Santo Tomás. Profesora del Centro de Formación Teológica de la Pontificia Universidad Javeriana. ORCID: 0000-0002-0793-862X. Correos electrónicos: malealevanava@ gmail.com malvaradon@javeriana.edu.co 


\title{
Approach of human dignity from theology in perspective of interculturality
}

\begin{abstract}
The interdisciplinary work between theology, politics, cultural studies and ethics, is necessary and useful for the current recognition of the necessary modifications in the epistemological statute of human rights. Dignity, at the core of this set of guarantees, involves the updating of defense paths that ensure that it is not just an abstraction, with which people of all nationalities and cultures are defined. It is the embodiment of changing realities, but with concrete faces. Theology from the perspective of interculturality, is presented as a place of reflection and instance of critique of the conservative and alienating ways of understanding and living dignity from the political and ethical spheres.
\end{abstract}

Keywords: dignity, rights, revelation, politics, interculturality, ethics of care.

\section{Abordagem da dignidade humana desde a teologia em perspectiva de interculturalidade}

\section{Resumo}

O trabalho interdisciplinar entre teologia, política, estudos culturais e ética, é necessário e útil para o reconhecimento atual das modificações necessárias no estatuto epistemológico dos direitos humanos. A dignidade, eixo central deste conjunto de garantias, supõe atualização de caminhos de defesa, que assegurem que não se trata sim mais de uma abstração, com a qual se define as pessoas de todas as nacionalidades e culturas. Senão que se trata da encarnação de realidades cambiantes, mas com rostos concretos. A teologia desde a perspectiva da interculturalidade apresenta-se como lugar de reflexão e instância de critica das conservadoras e alienantes maneiras de entender e viver a dignidade desde as esferas política e ética.

Palavras-chave: dignidade, diretos, revelação, política, interculturalidade, ética do cuidado. 


\section{Introducción}

Realizar un planeamiento del contenido de la dignidad humana, fundamentado en la comprensión de interculturalidad, que ofrezca un nuevo lugar de encuentro entre la teología y la política, exige llevar a cabo una revisión al bosquejo moderno de la epistemología de la dignidad, como componente esencial de los derechos humanos. Este esfuerzo confronta el contenido de tal noción como derecho, con la crítica que presenta del mismo, el sociólogo y teólogo Boaventura de Sousa Santos. Él establece que entre las políticas contrahegemónicas, las políticas de derechos humanos y las teologías políticas, es posible que haya un intercambio mutuamente enriquecedor, mediante el impulso que proporciona la interculturalidad en las luchas por la dignidad humana.

Sin embargo, el autor no menciona cuál es el contenido de la mencionada interculturalidad. De manera que, es fundamental esta indagación para, a su vez determinar cuál sería el posible contenido de la dignidad humana. Entran en juego las diferencias entre una ética de la justicia y una ética del cuidado que fundamenten la comprensión de la dignidad humana desde teología y la política, capaz de nutrirse de la interculturalidad.

En el primer apartado, La dignidad humana desde el planteamiento de los derechos humanos. Crítica a la dignidad como derecho fundamental, la construcción contractual de la dignidad humana, guiada por el estudio del teólogo José María Vigil, sobre la que se organiza la sociedad moderna, aparece la reflexión y toma de consciencia sobre el valor de la vida humana y los distintos elementos que le son constitutivos. Es sobre todo experiencia del liberalismo político como reacción a una sociedad estamental, en la que el honor determinaba el lugar político, económico y social de cada persona, haciéndola más o menos digna y nunca igual.

Se realiza un recorrido a partir de la Revolución francesa y los derechos del hombre desde la visión histórico-jurídica de Norberto Bobbio, que asume los elementos que configuraron la Declaración de los Derechos del Hombre de 1789. Posteriormente se hace una revisión de la Declaración Universal de los Derechos Humanos personales y sociales de 1948, con el fin de realizar una crítica necesaria al estatuto epistemológico y axiológico de la dignidad, a partir del discurso dirigido a la comunidad islámica, por parte del expresidente de los Estados Unidos, Barack Obama.

En el segundo apartado, el necesario papel contrahegemónico y ético de las teologías políticas, se realiza un ejercicio de análisis de las propuestas de Boaventura de Sousa Santos, el análisis de los derechos humanos de manera contrahegemónica, con el fin de llevar a cabo una evaluación crítica de los fundamentos de la 
superioridad ética y política de los discursos oficiales sobre los tales derechos, a partir de las cuatro ilusiones en las que están sumergidos. La salida a estas ilusiones es el papel contrahegemónico de las teologías políticas no fundamentalistas, sino pluralistas, en las cuales la concepción de la revelación, asume una postura concreta sobre la historia, la libertad y la participación política. Se plantea la necesidad de una revisión a la ética que da sustento a todo lo hasta aquí mencionado.

En el tercer apartado, Una reflexión teologica, política, ética e interculturada, como lugar de defensa de la dignidad humana, se trabaja a fondo la exhortación Evangelii Gaudium, con el fin de comprender cuál es el papel que juega la interculturalidad, en la relación entre teología, política y ética, con el pretexto de un planeamiento del contenido de la dignidad humana, que ofrezca un nuevo lugar de realización para la teología política.

\section{La dignidad humana desde el planteamiento de los derechos humanos}

En el presente apartado se aborda desde la historia, el derecho y la filosofía, los factores que contextualizan el surgimiento de la Declaración de los Derechos del Hombre de 1789 y de la Declaración Universal de los Derechos Humanos de 1948. Así mismo, se revisa la situación política que subyace a la institucionalización de las declaraciones y una crítica al estatuto epistemológico y axiológico de los derechos humanos.

\subsection{Construcción contractual de la dignidad}

El contractualismo político y el proceso de secularización anteriores al siglo XVIII, reorganizan la sociedad moderna, en torno a la dignidad humana. Esta es inviolable y mediante consenso, se reconoce a cada persona por encima de sus opciones, incluso religiosas: no importa si se trata del "disidente político, más aún, el ateo, ya no será un enemigo político, sino una persona humana dotada de la misma dignidad, con la que hay que colaborar para construir la sociedad" (Vigil, 1975, p. 7).

Pero el presupuesto que sostiene y orienta el sentido del conjunto de este cambio, y que constituirá un aporte definitivo a la historia humana, es la percepción de la relación intrínseca que existe entre política y libertad. De tal manera 
que, como expresa el teólogo José María Vigil, la libertad es manifestación sin duda, de la dignidad humana; lugar sobre el que se cierne la reflexión sociopolítica moderna y condición de posibilidad de su realización:

La "dignidad humana" ha encontrado finalmente en lo político una esfera digna del uso público de su libertad. En la sociedad humana ya no existe un "orden político", sino una "historia de la libertad". El orden político ya no es algo que está ahí, dado previamente al ser humano como si este debiera simplemente acomodarse a él. No hay un orden político; el orden político debe ser creado. Las estructuras políticas ya no están sustraídas a la voluntad del ser humano sino que, por el contrario, su historia debe dejar constancia de la historia de la libertad. Es el ser humano quien libremente construye su historia, y el ámbito político es el ámbito privilegiado de esta construcción (p. 9).

El viraje realizado es fundamental, porque la dignidad es asumida desde la esfera de lo público, mientras que la crítica al orden no supone optar por el caos. Se da primacía a la creación continua, de una historia que se va realizando, en la medida en que las libertades (libertad que cada persona agencia) confluyen. En ese sentido la política no corresponde a un orden superior, de carácter metafísico, sino que se constituye como una construcción y una responsabilidad.

Pero la dignidad humana es una formulación que nace en el contexto de una seria revisión de la teoría política y de Estado, sobre todo con los estudios de Locke, Montesquieu y Bentham. El espíritu del liberalismo político se cristaliza en las declaraciones de derechos, compañeras de todos los procesos revolucionarios. Autores y declaraciones consideran que, sobre la dignidad se construye de común acuerdo la sociedad; sobre todo, como acción de emancipación, por la cual "la humanidad se agita declarando ante sí misma sus propios derechos" (Vigil, 1975, p. 11).

Sin embargo, la declaración y aceptación de esta dignidad humana tiene consecuencias políticas inevitables, que sintonizaron y aún hoy, sintonizan a la base popular con ideas revolucionarias:

Los menos favorecidos económicamente exigirán nuevas condiciones económicas, los alejados del poder político pedirán participación, las colonias exigirán independencia, la exigencia de igualdad estará en la boca de todos, se abolirán los privilegios, se exigirá el reparto de lo acumulado injustamente... (p. 11).

De tal manera que, la dignidad no se configura como significante de suyo para las personas o para las comunidades. Ella depende de manera insoslayable 
de la presencia de otros factores que, configurados como derechos garanticen condiciones de realización de la libertad. Ente ellos son fundamentales, la eliminación de los privilegios en un primer momento, la igualdad en un segundo paso y posteriormente la equidad.

La revolución liberal burguesa de finales del siglo XVIII nació como fruto del rompimiento de aquellos factores que dieron forma a la sociedad estamental. Ello planteó la radical necesidad de hacer consciencia de la dignidad y asumir la capacidad de superar las alienaciones. Este orden naciente "no se presenta como un reino utópico e imposible sino, por el contrario, como algo que está sujeto al dominio de nuestra voluntad, como un proyecto social del que es posible responsabilizarse" (p. 12).

Nociones y realidades que dan lugar a la desigualdad y a la discriminación, tales como el honor, principio que diferencia y encuadra en estamentos a la sociedad, profundizando la injusticia y propiciando privilegios económicos y jurídicos injustificados, arremeten contra la necesidad del reconocimiento del valor que se tiene por el hecho de ser humano. Es la ley, la instancia que garantiza la afirmación de todos los seres humanos como iguales, con la misma dignidad, y establece cualquier tipo de desigualdad social como injustificable. El noble ideal que subyace a esta sociedad es la fraternidad y la solidaridad.

El pueblo entero será soberano, porque el pueblo entero comulga en la misma dignidad natural. Todo el pueblo es libre y todos participan de la misma responsabilidad. Todos están embarcados en la misma aventura. En esta fraternidad política todos deben participar. Al menos, todos pueden. Y como el silencio también repercute en la elaboración de la voluntad popular, hasta la abstención es acto político (p. 15).

\subsection{La Declaración de los Derechos del Hombre y la dignidad}

Norberto Bobbio (1909-2004) jurista, filósofo y politólogo italiano, sigue al historiador francés Georges Lefebvre al asumir que "proclamando la libertad, la igualdad y la soberanía popular, la Declaración constituyó el acta de defunción del antiguo régimen, destruido por la Revolución" (Bobbio, 1991, p. 132). Se refiere con ello, a la Declaración de los Derechos del Hombre que originó la Revolución francesa.

Siguiendo al político francés Alexis de Tocqueville, Bobbio describe la primera fase de 1789 como un tiempo de "entusiasmo juvenil, de arrogancia, de 
pasiones generosas y sinceras, de las que, a pesar de cualquier error, los hombres guardarían eterna memoria, y que, por mucho tiempo todavía, turbará los sueños de aquellos a quienes los hombres quieren dominar o corromper" (1991, p. 132).

Este entusiasmo siguiendo a Kant, se entiende como la "revolución de un pueblo rico, en espiritualidad, que aun habiendo podido acumular miseria y crueldad, había encontrado sin embargo “una participación de aspiraciones" (p. 132), traducidas en el hecho de que un pueblo se da una Constitución civil que considera buena. La revolución se conecta con el derecho que tiene un pueblo a decidir su destino, dándose una legislación, ejerciendo su libertad, mediante la autodeterminación, la autonomía, rechazando toda forma de poder paternal o patriarcal.

El centro doctrinal de la Declaración de los Derechos del Hombre y del Ciudadano de 1789 está contenido en los primeros tres artículos. En el primero la condición natural de los individuos, en el segundo, el fin de la sociedad política que viene después del estado de naturaleza, y en el tercero, el principio de legitimidad del poder que corresponde a la nación (Declaración de los Derechos del Hombre y del Ciudadano, 1789).

El primer artículo: “Los hombres nacen y permanecen libres e iguales en derechos. Las distinciones sociales solo pueden fundarse en la utilidad común" (1789, Art. 1), implica más que un debate como el planteado por Rousseau, sobre si se trata de un nacimiento no natural o ideal. Se trata de la manifestación de una hipótesis racional secular (no de la constatación de un hecho o de un dato histórico) por la cual, el poder político, el poder sobre los hombres y el imperium, no proceden de arriba abajo sino al contrario (Bobbio, 1991).

\subsection{La Declaración Universal de los Derechos Humanos personales y sociales de 1948}

La Declaración Universal de los Derechos Humanos de 1948, establece que "la libertad, la justicia y la paz en el mundo tienen por base el reconocimiento de la dignidad intrínseca y de los derechos iguales e inalienables de todos los miembros de la familia humana" (ONU, 1948). Ello en contraposición a la barbarie y ultrajantes que conllevaron y conllevan al desconocimiento y menosprecio del valor de las personas; pero en consideración de la liberación del temor y de la miseria, como aspiración de los hombres.

Esta declaración promueve "el desarrollo de relaciones amistosas entre las naciones" (ONU, 1948), de tal modo que, los Estados miembros se comprometen a asegurar, en cooperación con la Organización de las Naciones Unidas, “el 
respeto universal y efectivo a los derechos y libertades fundamentales del hombre" (ONU, 1948, Preámbulo). Esta declaración tiene un carácter inspirador tanto para individuos como para instituciones, en el reconocimiento y aplicación universal y efectiva de las garantías mencionadas.

Los tres valores éticos absolutos que asumen las naciones miembros con esta declaración, son la dignidad humana, la solidaridad y la justicia:

Por ello en tal declaración toda la humanidad se compromete en hacer efectivos para todas las mujeres y hombres sin ningún tipo de exclusión, estos valores, es decir el reino o la comunidad de los fines, la cristalización real de los tres absolutos mencionados, acción comunicativa y mínimo ético universal efectivos, alteridad ${ }^{1}$ por antonomasia (Novoa, 2016, p. 13).

Se asume como cierto aquello que afirma Carlos Novoa:

$\mathrm{Al}$ interior de varias escuelas de la ciencia ética creemos que la Declaración Universal de los Derechos Humanos personales y sociales de 1948 son un buen primer consenso ético mínimo mundial el cual deberá evolucionar con el correr de los tiempos, las culturas y las sociedades (2016, p. 3).

En consonancia, se sostiene que el asunto de la dignidad no hay que repensarlo para debatir su validez, porque es una ganancia que la humanidad reconoce como favorable, buena y justa. Pero sí es necesario deconstruir la fisonomía que adquirió por estar enmarcada dentro de los límites de los Estados miembros, categoría encargada de abstraer la noción de ser humano e imponer una alabada e inexistente igualdad en todos los sentidos, entre los ciudadanos de todas las naciones.

Es necesaria la reconstrucción de la dignidad, pero desde la calidez y la aridez propias de interculturalidad, en clave de afirmación de la identidad. Porque es un hecho que, en buena parte de los países del mundo "los derechos fundamentales no se cumplen, y en el llamado tercer mundo (más de la mitad de la Tierra), estos derechos son seriamente vulnerados" (pp. 3-4). Hay sistematicidad en la transgresión de los derechos, en directa relación con el fenómeno cada

1 "Se trata de que nos enamoremos y nos dejemos llevar por la fraternidad rechazando el individualismo. De esta forma la alteridad se coloca en el centro de la experiencia y la ciencia ética, y buena parte de las diversas escuelas morales actuales la asumen" (Novoa, 2016, p. 3). 
vez más extendido de la corrupción; es inevitable la realidad de una violencia institucionalizada.

Sin embargo, el expresidente de los Estados Unidos de América declara:

Mientras nuestra relación sea definida por nuestras diferencias, les otorgaremos poder a quienes siembran el odio en vez de la paz, y a quienes promueven el conflicto en vez de la cooperación que puede ayudar a todos nuestros pueblos a lograr la justicia y la prosperidad. Este ciclo de suspicacia y discordia debe terminar.

He venido aquí a buscar un nuevo comienzo para Estados Unidos y musulmanes alrededor del mundo, que se base en intereses mutuos y el respeto mutuo; y que se base en el hecho de que Estados Unidos y el islam no se excluyen mutuamente y no es necesario que compitan. Por el contrario: coinciden en parte y tienen principios comunes, principio de justicia, progreso, tolerancia y el respeto por la dignidad de todos los seres humanos (Obama, 2009).

Se está de acuerdo, sin duda con el primer párrafo en tanto el odio hace que las personas entren en ciclos cerrados de repetición que no terminan e incorporan violencia. Sin embargo, no se comparte que, la promoción del conflicto se oponga a la cooperación, porque ello traería de suyo, la necesidad de erradicar las diferencias que son las que generan conflicto. Menos aun cuando se trata de identidades diferentes, que entienden de manera distinta los principios de justicia y progreso. Cada cultura vive de manera diversa y pone en marcha recursos disímiles para la consecución de la paz y la prosperidad, propios de sus coordenadas temporales y espaciales, religiosas, axiológicas, políticas, sociales, económicas y de desarrollo.

Obama propone partir de la condición de igualdad, que a todas luces es el ideal entre el islam y Estados Unidos, regiones y tradiciones que no se pueden calcular con la misma medida, y mucho menos nominar como amistosas y cooperantes en la defensa, respeto y garantía de los derechos humanos. Menos cuando a partir de los atentados del 11 de septiembre del 2001, se organizó una coalición internacional en contra de las naciones pertenecientes al islam.

No se explica cómo este mandatario parte de la no diferencia teórica y práctica. A menos que se comprenda el contexto de Estados Unidos: una nación hegemónica y colonizadora, con suficiente poder económico y militar como para pretender la coincidencia de principios tales como la justicia, el progreso, la 
tolerancia y el respeto por la dignidad. Lo que acaece es la imposición de una única comprensión en la defensa y violación de principios.

\section{El necesario papel contrahegemónico y ético de las teologías políticas}

Después de problematizar el núcleo de los derechos humanos en el conjunto de elementos y discursos que los acompañan y avalan, se presentan dos teólogos políticos iberoamericanos, el portugués Boaventura de Sousa Santos y el brasilero Leonardo Boff, quienes hacen una crítica a los discursos políticos y éticos dominantes sobre la dignidad, no desde la preocupación por hacer parte del estado del arte sobre los derechos humanos y la dignidad, sino desde la preocupación por la violación sistemática de la dignidad vivida en diferentes culturas; ello pone sobre la mesa otras maneras de hacer teología política y una ética alternativa al imperio exclusivo de la ética de la justicia.

\subsection{Las ilusiones de los derechos humanos}

Boaventura de Sousa Santos (2014) establece que:

Hoy no se pone en tela de juicio la hegemonía global de los derechos humanos como discurso de la dignidad humana. Sin embargo, esa hegemonía convive con una realidad perturbadora; la gran mayoría de la población mundial no constituye el sujeto de los derechos humanos, sino más bien el objeto de los discursos sobre los derechos humanos. La cuestión es, en consecuencia, si los derechos humanos son eficaces en ayudar a las luchas de los excluidos, los explotados y los discriminados, o si, por el contrario, las hace más difíciles. En otras palabras: ¿la hegemonía de la que goza hoy el discurso de los derechos humanos, es el resultado de una victoria histórica, o más bien de una histórica derrota? (p. 13).

De allí nace la pregunta sobre si es posible analizar la comprensión y defensa de los derechos humanos de modo contrahegemónico. Si existen otros discursos sobre la dignidad humana y en qué medida son compatibles con aquellos sobre los derechos humanos. Metodológicamente, ello implica acudir a una 
hermenéutica de la sospecha sobre todo respecto de las concepciones cercanas a la política occidental y liberal.

El problema fundamental es que la antropología de la que beben el concepto de ley y derecho, se adecuaba al individualismo burgués en auge, propio de la teoría liberal y del capitalismo. Los derechos humanos tienen raíces hegemónicas muy profundas, que los han consagrado como principios reguladores de una sociedad justa, en torno a la cual se consolidó la idea de consenso, que para de Sousa:

Se manifiesta en diversas formas, cada una de las cuales se basa en una ilusión. Debido a que son ampliamente compartidas, tales ilusiones constituyen el sentido común de los derechos humanos convencionales. Yo distingo cuatro ilusiones: teleología, triunfalismo, descontextualización y monolitismo (p. 15).

La teleología de los derechos humanos es ilusoria porque hace una lectura lineal de la historia pasada, partiendo de un pretendido consenso sobre los derechos humanos y el bien que ostentan, se concluye que el hoy y la dignidad humana son su resultado determinista, no contingente. El triunfalismo es una ilusión que afirma que la idea de "victoria de los derechos humanos es un bien humano incondicional" (p. 16); en este sentido, otros discursos éticos y políticos no oficiales sobre la dignidad humana, se tienen como inferiores. Por ello, es necesario de un lado hacer una evaluación crítica a los fundamentos de superioridad ética y política de las disertaciones actuales sobre los derechos humanos, y de otro lado, revisar los discursos vencidos que, al ser lenguaje de emancipación cultural, son merecedores de valía.

La ilusión de la descontextualización, devela que los derechos humanos se reconocen como discurso emancipador, originado en la Ilustración del siglo XVIII, en la Revolución francesa y en la Revolución americana. Desconociendo que hasta hoy, los derechos humanos se usan en distintos contextos y con objetivos contradictorios para legitimar prácticas tales como revoluciones o invasiones, que cabe considerar violaciones de los derechos humanos. De Sousa llama a este fenómeno: hipocresía constitutiva.

Finalmente, el monolitismo es la ilusión que niega las contradicciones internas de los derechos humanos. De tal manera que, al invocarlos se apela con generosidad, a la inclusividad de la humanidad, pero cuando se habla de ciudadanos, tal generosidad es mucho más restrictiva, porque se circunscribe a un determinado Estado. Desde cualquier punto de vista no hay igualdad a pesar de la generosidad. 


\subsection{Teologías políticas pluralistas: salida contrahegemónica a las cuatro ilusiones}

Con el término contrahegemónico se denotan las luchas, movimientos e iniciativas, que tienen por objeto la eliminación de las desiguales relaciones de poder, transformándolas en relaciones de autoridad compartidas. Es necesario el prefijo contra, porque lo no hegemónico refiere aquellas

Actuaciones sociales (luchas, iniciativas y prácticas) que resisten frente a las formas hegemónicas de dominación y sus formas de comprensión liberales, pero que aspiran a reemplazarlas por otras formas de dominación que reproducirán, o incluso agravarán, las desiguales relaciones sociales de poder (De Sousa, 2014, p. 28).

Las teologías políticas corren el riesgo de relacionarse con la esfera pública y privada, y con la organización de la vida social y política, de manera no hegemónica, es decir, sin enfrentarse al capitalismo, al colonialismo o al sexismo; por el contrario, atribuyéndoles justificación divina:

Por un lado, se reconocieron los valores cristianos como universales; por otro, se relegó el cristianismo institucional al gobierno de la esfera privada, la esfera de las decisiones autónomas y voluntarias de los individuos. Esta solución occidental de la cuestión religiosa está siendo puesta en tela de juicio por el auge de la religión en la vida pública en muchas partes del mundo, incluido el mundo occidental, y se traduce en la reivindicación del papel de la religión en la vida pública (p. 29).

Esta distinción entre lo público y lo privado, y la relegación de la religión a este último, se problematiza hoy en el plano de la regulación social y en el de la emancipación social. Ello mismo ocurre con los derechos naturales del siglo XVIII, con el constitucionalismo moderno, con los derechos humanos y con las declaraciones de las Naciones Unidas. Se pone en tela de juicio el localismo globalizado, por el cual, una solución local en virtud del poder económico, político y cultural, se expande a todo el globo.

De Sousa define la teología política como "los diferentes modos de concebir la intervención de la religión, en tanto mensaje divino, en la organización social y política de la sociedad" (p. 30). En el siglo pasado este campo de estudio era la instancia crítica, encargada de sancionar las estructuras sociales y políticas existentes. En general, las teologías políticas cuestionan la separación moderna de 
lo privado y lo público, y demandan la intervención de la religión en esta última. En este sentido, es necesario hacer la distinción entre teologías pluralistas y fundamentalistas:

Según las teologías fundamentalistas, la revelación es un discurso divino eterno, increado, y toda interpretación humana no puede ser, en consecuencia, más que una reducción sacrílega. Las teologías pluralistas conciben la revelación como una contribución a la vida pública y a la organización política de la sociedad, pero aceptan la autonomía de ambas. Manejan la tensión entre la razón y la revelación procurando mantener un equilibrio entre ellas. Aunque divina e inconmensurable con la razón humana, la revelación tiene como único propósito ser accesible a la razón humana y ser cumplida por la acción humana de la historia. Esto sería imposible si los seres humanos fuesen incapaces de pensamiento creativo y de acción autónoma. En suma, las teologías pluralistas apuntan a una concepción humana de la religión. Dos temas de mayor importancia están en juego en la distinción entre las teologías pluralistas y las fundamentalistas: la relación entre razón y revelación, y la relación entre revelación e historia (p. 33).

Para las teologías pluralistas, la revelación acontece en un contexto social y político dado, abierto a nuevos contextos, en respuesta a las necesidades sociales y existenciales de un determinado tiempo; se trata de "una religión en la historia" (p. 34). Para las teologías fundamentalistas, la revelación es eterna, sin contexto, por lo tanto, contiene en sí misma todas las necesidades históricas; es "una historia dentro de la religión" (p. 34). En consecuencia, las teologías pluralistas cristianas no aceptan la separación Estado-sociedad civil; se rechazan el monopolio del Estado en la organización social y la sociedad civil como esfera privada; por el contrario, la sociedad civil es un espacio público no estatal.

Se enfrenta la ideología de la autonomía y del individualismo, mediante los derechos humanos y las teologías políticas. Los primeros como "gramática decisiva de la dignidad humana, hasta la década de los años setenta y ochenta del pasado siglo" (p. 10), las segundas como "concepciones de la religión que parten de la separación de las esferas pública y privada, y que demandan la presencia (mayor o menor) de la religión en la esfera pública" (p. 10).

Los derechos humanos son individualistas, seculares, culturalmente occidentocéntricos y estadocéntricos, "las teologías políticas por el contrario, son comunitarias, antiseculares. Pueden ser tanto prooccidentales como implacablemente 
antioccidentales, y tienden a ser hostiles al Estado" (p. 11). Parecen tener nada en común, tanto los unos como las otras:

Precisamente a partir de esta diversidad y de la complejidad que emerge de la misma, intento realizar un ejercicio de traducción intercultural entre estas dos políticas normativas, y busco zonas de contacto traductivo entre ellas que sean capaces de aportar nuevas o renovadas energías para la transformación radical y progresista (p. 11).

Lo interesante de este asunto, es evidenciar que a la base están las creencias religiosas y espiritualismos de índole religiosa, es decir, las "subjetividades políticas que parecen haber abandonado el pensamiento crítico occidental y la acción política secular que de él se deriva" (p. 11). Lejos de apartar de las luchas materiales son perfectamente terrenales, trabajan en pro de otro mundo posible.

\subsection{La ética integral de lo masculino y lo femenino}

Lo dicho hasta aquí es insuficiente, hay que adentrarse en las éticas marcadas por las culturas, que determinan los paradigmas presentados. Leonardo Boff encuentra que el cuidado responde a la estructura constitutiva del ser humano (y se hace necesaria ante la crisis ecológica planetaria hoy), siguiendo al filósofo Martin Heidegger con su formulación del sorge, como esencial al Dasein (Heidegger, 2014). Pero entonces ¿qué hacer con el paradigmático y dominante discurso ético de la justicia, propio de los derechos humanos, de las teologías políticas fundamentalistas y de las teologías políticas pluralistas? Hay que decir que cuidado y justicia tienen lógicas diferentes que se componen en medio de la complejidad.

El teólogo brasilero identifica la reciprocidad y complementariedad entre lo masculino como ética de la justicia y lo femenino como ética del cuidado femenino y masculino:

Nacen de datos reales y no imaginados, como dos fuentes distintas que, juntas, colaboran en la producción del agua cristalina de la ética humana. Ambas constituyen una ética integral y globalizadora de la experiencia humana. Por eso ninguna de ellas puede excluirse o contraponerse a la otra. Necesitamos las dos (Boff, 2012, p. 77). 
La justicia es lugar determinante para la defensa a nivel personal y social de la dignidad humana, es necesaria para garantizar una convivencia pacífica en todos los pueblos y es herramienta de construcción del bien común. Se ha identificado solamente con la ley, sin embargo, es el justo medio que, aun prescindiendo de la ley, hace a todos los ciudadanos igualmente dignos; "mas ya Platón notaba que una sociedad que se construye solamente sobre la justicia puede volverse cruel y sin piedad. Vale el antiguo adagio: summum ius, summa iniura: 'el exceso de derecho genera el exceso de la ofensa'" (p. 77).

Las instituciones y leyes se ven desbordadas por la generosidad y creatividad de las personas. Esta capacidad de valorar la vida por encima de la ley o epiqueia, es la fuente de nacimiento del cuidado. Se evidencia que, cuando las relaciones humanas son determinantes, cuando es imperante proteger la vida, sanar las heridas pasadas y prevenir las futuras, se atiende y defiende la dignidad de las personas, no como discurso hegemónico, no como postulado teorético, sino como realidad que apremia:

El cuidado nos convence de que una ética que parte de la absoluta autonomía del sujeto en la soledad de su libertad es una irrealidad y una ilusión. No es más que una abstracción. Para que los seres humanos así solitarios puedan vivir juntos necesitan un contrato social como fue elaborado por Rousseau, Locke o Kant en los tiempos modernos.

Cuando, por el contrario, partimos del hecho real de que el ser humano es siempre un ser de relación, que su ser es un ser-con-los-otros, en el cuidado y en la preocupación, el contrato social se vuelve relativo, necesario en una sociedad de clases que necesitan establecer acuerdos para no devorarse mutuamente, pero en realidad presupone el carácter social de los seres humanos, que naturalmente, con o sin contrato, tienden a vivir juntos (p. 78).

El cuidado como dimensión ontológica, antropológica y necesariamente teológica, es rica en tanto se gesta en el ámbito relacional. El cuidado no es un postulado, es un gesto, una acción de salida generosa de sí, y de recibimiento amoroso del otro. Cosa que solo ocurre en la vida cotidiana, en las tareas familiares, entre amigos, entre quienes lo necesitan. En estos lugares ha de garantizarse la dignidad del otro y la propia. 


\section{Una reflexión teológica, política, ética e interculturada, como lugar de defensa de la dignidad humana}

La ética del cuidado fundamenta una comprensión de la dignidad humana, realizable en la teología política desde la encarnación de Dios en la historia, expresada en el compromiso efectivo del creyente con aquellos a quienes les son vulnerados sus derechos. Por su parte, la interculturalidad es asunto trasversal a la pedagogía, la antropología, la teología y la fe; impulsado por la defensa de los derechos de los pueblos indígenas, afro y gitanos. Es un paradigma tan relevante, que incluso en políticas públicas sobre educación se ha asumido, tal como se constata en la documentación de la UNESCO². Hay un fuerte interés por las tensiones entre lo local y lo global, fijándose especialmente en las culturas y sus necesidades específicas.

\subsection{Dignidad desde la cultura de la globalización}

La interculturalidad es motivo de diálogos e investigaciones interdisciplinares con diferentes propósitos, tal como se constata en la exhortación apostólica del papa Francisco, Evangelii Gaudium ${ }^{3}$. Aunque la exhortación presta atención a los cambios culturales con el fin de "intentar expresar las verdades de siempre en un lenguaje que permita advertir su permanente novedad" (Francisco, 2013, N 41), la mirada sobre la cultura no es instrumental, por el contrario, se centra en la preocupación por reconocerla como lugar en el cual cada uno quiere ser portador de la propia verdad subjetiva, ello impide que los ciudadanos integren un proyecto común que supere los beneficios y deseos personales.

La teología se fija en la cultura con el fin de replantear la dignidad en contexto, más que como concepto gestado en un momento histórico, actualizado por naciones dominantes, económicamente desarrolladas, pero éticamente debilitadas, que gracias a la globalización han deteriorado las raíces culturales de otras naciones. Así como establecen los obispos africanos, en la encíclica Sollicitudo rei socialis:

2 Organización de las Naciones Unidas para la Educación, la Ciencia y la Cultura.

3 Si bien la exhortación hace referencia a la parroquia, es necesario que se entienda a la Iglesia en su sentido más amplio, arraigado más a la cultura que a lo eclesial. 
Los países subdesarrollados, en vez de transformarse en naciones autónomas, preocupadas de su propia marcha hacia la justa participación en los bienes y servicios destinados a todos, se convierten en piezas de un mecanismo y de un engranaje gigantesco. Esto sucede a menudo en el campo de los medios de comunicación social, los cuales, al estar dirigidos mayormente por centros de la parte norte del mundo, no siempre tienen en la debida consideración las prioridades y los problemas propios de estos países, ni respetan su fisonomía cultural; a menudo, imponen una visión desviada de la vida y del hombre y así no responden a las exigencias del verdadero desarrollo (Juan Pablo II, 1987, N²2).

Este diagnóstico pone en relación las culturas local y global, develando que su tensión coloca en peligro la dignidad de los pueblos y sus valores tradicionales, sobre construcciones artificiales amarradas a lo político. Por eso, a la fe no solo le interesa asumir la cultura para defenderse de la proliferación de nuevos movimientos religiosos, de fundamentalismos y del mercado de la espiritualidad. Le ocupan "las carencias de la población que vive en las periferias y zonas empobrecidas, que sobrevive en medio de grandes dolores humanos y busca soluciones inmediatas para sus necesidades" (Francisco, 2013, N 63).

Porque la opción fundamental de los seguidores de Cristo incluye la preocupación y determinación por el agenciamiento político de la persona, sea esta creyente o no. Porque el Evangelio exige asumir una postura de construcción social, frente a las realidades de opresión. Con las cosas así, no puede insistirse más en "la existencia de normas morales objetivas, válidas para todos" ( $\left.\mathrm{N}^{\circ} 64\right)$, pero tampoco en la creencia en los derechos absolutos de los individuos. Sin embargo, la Iglesia es mediadora y defensora directa de los derechos humanos y ciudadanos:

La acción pastoral debe mostrar mejor todavía que la relación con nuestro Padre exige y alienta una comunión que sane, promueva y afiance los vínculos interpersonales. Mientras en el mundo, especialmente en algunos países, reaparecen diversas formas de guerras y enfrentamientos, los cristianos insistimos en nuestra propuesta de reconocer al otro, de sanar las heridas, de construir puentes, de estrechar lazos y de ayudarnos "mutuamente a llevar las cargas" (Ga 6,2). Por otra parte, hoy surgen muchas formas de asociación para la defensa de derechos y para la consecución de nobles objetivos. Así se manifiesta una sed de participación de numerosos ciudadanos que quieren ser constructores del desarrollo social y cultural ( $\left.\mathrm{N}^{\circ} 67\right)$. 
El individualismo posmoderno y globalizado, lleva a nuevas violaciones de la dignidad humana, por eso es escenario desde el cual pensar nuevas condiciones culturales, económicas, sociales, familiares y eclesiales, en fidelidad a las convicciones sobre la dignidad humana y el bien común.

\title{
3.2. Reconocimiento de la fe con el pretexto de la defensa de la dignidad
}

La cultura y la interculturalidad son una realidad viva, de la que hacen parte los dramas de los más necesitados, el hambre por los valores del humanismo cristiano y la sed de solidaridad y justicia. En este sentido, la imperiosa necesidad de evangelizar las culturas para inculcar el Evangelio, no tiene como pretexto primordial la fe, sino la defensa de la dignidad humana, de la promoción social y la formación, "la solidaridad, la fraternidad, el deseo de bien, de verdad, de justicia" (Francisco, 2013, N 71). Porque

\begin{abstract}
Nuevas culturas continúan gestándose en estas enormes geografías humanas en las que el cristiano ya no suele ser promotor o generador de sentido, sino que recibe de ellas otros lenguajes, símbolos, mensajes y paradigmas que ofrecen nuevas orientaciones de vida, frecuentemente en contraste con el Evangelio de Jesús. Una cultura inédita late y se elabora $\left(\mathrm{N}^{\circ} 73\right)$.
\end{abstract}

Para ello, más que "espacios de oración y de comunión con características novedosas, más atractivas y significativas para los habitantes urbanos y rurales" $\left(\mathrm{N}^{\circ} 73\right)$, se requiere tender puentes de comunicación con las autoridades y con los movimientos sociales que permitan la lucha por la dignidad. Así se llega donde se gestan los nuevos relatos y paradigmas, a saber, a los ámbitos multiculturales, a territorios culturales, a ciudades invisibles, en las que se ejerce la segregación y la violencia con "los 'no ciudadanos', los 'ciudadanos a medias' o los 'sobrantes urbanos'” ( $\left.\mathrm{N}^{\circ} 74\right)$.

La proclamación del Evangelio será una base para restaurar la dignidad de la vida humana en esos contextos, esta es una comprensión flexible de evangelización, capaz de vivir a fondo lo humano e introducirse en el corazón de los desafíos como fermento testimonial. Ello en cualquier cultura, en cualquier ciudad, mejora al cristiano y fecunda la cultura. 
La noción de cultura es una valiosa herramienta para entender las diversas expresiones de la vida cristiana que se dan en el Pueblo de Dios. Se trata del estilo de vida que tiene una sociedad determinada, del modo propio que tienen sus miembros de relacionarse entre sí, con las demás criaturas y con Dios. Así entendida, la cultura abarca la totalidad de la vida de un pueblo. Cada pueblo, en su devenir histórico, desarrolla su propia cultura con legítima autonomía ....El ser humano está siempre culturalmente situado: "naturaleza y cultura se hallan unidas estrechísimamente". La gracia supone la cultura, y el don de Dios se encarna en la cultura de quien lo recibe ( $\left.\mathrm{N}^{\circ} 115\right)$.

Así, los pueblos experimentan el don de Dios según su propia cultura, en un ejercicio de admiración de rostros pluriformes, en los que se hace presente el Espíritu Santo, la revelación muestra nuevos aspectos y se vive de pluriformes maneras el Evangelio. Entonces, ¿por qué hablando de los derechos humanos y del Evangelio se impone una determinada forma cultural, aunque sea bella y antigua? ¿Cayendo en la vanidosa sacralización de una determinada manera de legitimar una cultura transnacional, sin tener en cuenta tradiciones y culturas de distintas regiones? En cuanto a los derechos y al Evangelio, no se puede pedir la imitación de pueblos europeos, porque "una sola cultura no agota el misterio de la redención de Cristo" ( $\left.{ }^{\circ} 117\right)$, ni agota los frentes de defensa de los derechos humanos.

\subsection{Cuidar la fragilidad es sinónimo de cuidar la dignidad}

La inquietud cristiana por la dignidad es la preocupación por el cuidado de la fragilidad de los más pequeños, es decir, "los sin techo, los toxicodependientes, los refugiados, los pueblos indígenas, los ancianos cada vez más solos y abandonados, etc." (Francisco, 2013, N²10), también los migrantes. La teología se puede responsabilizar de impulsar la integración y el reconocimiento de la dignidad de quienes tienen menores posibilidades de defender sus derechos; se trata de defender sus vidas con

La convicción de que un ser humano es siempre sagrado e inviolable, en cualquier situación y en cada etapa de su desarrollo. Es un fin en sí mismo y nunca un medio para resolver otras dificultades. Si esta convicción cae, no quedan fundamentos sólidos y permanentes para 
defender los derechos humanos, que siempre estarían sometidos a conveniencias circunstanciales de los poderosos de turno. La sola razón es suficiente para reconocer el valor inviolable de cualquier vida humana, pero si además la miramos desde la fe, "toda violación de la dignidad personal del ser humano grita venganza delante de Dios y se configura como ofensa al Creador del hombre" ( $\left.\mathrm{N}^{\circ} 213\right)$.

La coherencia del mensaje sobre el valor de la persona humana, supone aceptar y partir de la diversidad, en "una especie de pacto cultural que haga emerger una 'diversidad reconciliada'" ( $\left.\mathrm{N}^{\circ} 230\right)$. Mientras que la realidad es, la idea se elabora; y aunque realidad e idea dialoguen para no separarse, en todo caso la realidad supera la idea. Entonces la realidad no puede ocultarse con purismos, totalitarismos, nominalismos, proyectos, fundamentalismos, eticismos e intelectualismos. Porque la idea "está en función de la captación, la comprensión y la conducción de la realidad" ( $\mathrm{N}^{\circ} 232$ ). Así tampoco política, fe, ética y teología pueden reducirse a la retórica y desvincularse de la cultura.

La teología nace de la cultura y de la fe, es política y ética, encarna la Palabra y la pone en práctica, para buscar el reconocimiento y restauración del otro y su bien $\left(\mathrm{N}^{\circ} 9,75\right)$, confesar la adhesión del amor al Padre y la asunción del Hijo hasta la cruz, confiere una dignidad infinita, redime al sujeto y las relaciones sociales entre los hombres. Porque el Evangelio no propone solo una relación personal con Dios, y no se trata de gestos personales de caridad con unos individuos necesitados. La propuesta del Reino "se trata de amar a Dios que reina en el mundo. En la medida en que Él logre reinar entre nosotros, la vida social será ámbito de fraternidad, de justicia, de paz, de dignidad para todos" $\left(\mathrm{N}^{\circ} 180\right)$. Es menester pues, que los derechos humanos no sean garantías de los individuos o de los pueblos más ricos, hay que fijarse en los lugares con menores recursos o menor desarrollo, para que vivan con no menor dignidad, incluso si ello supone que los más favorecidos renuncien a algunos de sus derechos.

Pero queremos más todavía, nuestro sueño vuela más alto. No hablamos solo de asegurar a todos la comida, o un "decoroso sustento", sino de que tengan "prosperidad sin exceptuar bien alguno". Esto implica educación, acceso al cuidado de la salud y especialmente trabajo, porque en el trabajo libre, creativo, participativo y solidario, el ser humano expresa y acrecienta la dignidad de su vida. El salario justo permite el acceso adecuado a los demás bienes que están destinados al uso común $\left(\mathrm{N}^{\circ} 192\right)$. 
Una teología política que nace de la experiencia del Evangelio, hace de la defensa de la dignidad de cada persona humana y el bien común, su compromiso, objetivo y sentido. Se ocupa creativamente, política y proféticamente de que los pobres vivan con dignidad. Porque en efecto, "no hay decisiones técnicas, estas son de carácter político y conllevan un hondo talante ético" (Novoa, 2017, p. 1). Consciente de ello, "la Iglesia se hace pregonera de los derechos fundamentales de cada persona" (Benedicto XVI, 2007, $\mathrm{N}^{\circ}$ 2).

Es necesario cultivar la teología de manera conjunta con las otras ciencias. Se requiere del trabajo interdisciplinar, que enriquezca la teología y la política misma, no solo en su estatuto epistemológico, sino en sus praxis. Solo así, se comprende que toda acción humana y política son cristianas; de esta forma la teología no se abstrae del ejercicio político.

Es un reto establecer la importancia de la formación política de los teólogos, para que amplíen el concepto de política y lo incorporen como parte constitutiva de la teología, y lograr una convergencia activa y dinámica entre creyentes y no creyentes:

La política, tan denigrada, es una altísima vocación, es una de las formas más preciosas de la caridad, porque busca el bien común. Tenemos que convencernos de que la caridad no es solo el principio de las micro-relaciones, como en las amistades, la familia, el pequeño grupo, sino también de las macro-relaciones, como las relaciones sociales, económicas y políticas (Francisco, 2013, № 205).

Mal entendida, la política se reduce a la participación mediante el voto en la elección de los cargos de representación popular. Pero hay una responsabilidad importante heredada desde Aristóteles, al entendernos como zoon politikon, constitutiva de las relaciones que se establecen con los congéneres. Con ello "queda claro entonces que la Iglesia debe implicarse en el desarrollo de la alta política, o sea de la construcción de la plena e integral realización de todas las dimensiones que conforman la persona y la sociedad" (Novoa, 2017, p. 4).

La filiación y la fraternidad divinas nos exigen conformar un orden económico, político, social y cultural sin excluidos y donde todos puedan realizar y satisfacer todas sus capacidades y necesidades.

Esta radical dignidad e igualdad de toda mujer y varón con la fraternidad que le es inherente desde la vivencia cristiana, nos lanza a colocar 
en el centro tanto la persona como la comunidad humana en todo el devenir de nuestra praxis política. Por esto el servicio al otro marca la construcción de la polis desde el Evangelio, y de esta radical dignidad, igualdad y fraternidad nace el talante solidario, la opción preferencial por los pobres, la dinámica consensual, la soberanía popular y el bien común en la construcción de la polis por parte del creyente (Novoa, 2017, p. 7).

El quid está en la búsqueda del bien común y en la finalidad cristocéntrica, para empeñarse en la construcción de una comunidad política plenamente humana. Para el cristiano, el amor generoso implica su inserción leal en la sociedad y en la actividad política, que se ocupa de las necesidades de la gente. La teología no solo realiza aportes epistemológicos propios de la reflexión de la experiencia de fe que la sostienen, aporta fundamentalmente la experiencia comunitaria a la que está referida.

La reflexión de la teología política sobre la dignidad, no nace de un deber ser, sino de lugares concretos:

Necesitamos instaurar esta cultura del encuentro, porque ni los conceptos ni las ideas se aman. Nadie ama un concepto, nadie ama una idea; se aman las personas. La entrega, la verdadera entrega surge del amor a hombres y mujeres, niños y ancianos, pueblos y comunidades... rostros, rostros y nombres que llenan el corazón" (Francisco, 2017).

En este sentido no es posible establecer recetas, y menos cuando no hay inserción en comunidades concretas, si el papa pide que no se esperen de él recetas, mucho menos de la teología política. En la labor de devolverles a los pobres y a los pueblos la dignidad que les pertenece "los movimientos populares tienen un rol esencial, no solo exigiendo y reclamando, sino fundamentalmente creando... viviendas, productores de alimentos, sobre todo para los descartados por el mercado mundial" (Francisco, 2017). De tal manera que, más que insertar una teoría sobre la dignidad a partir de la teoría de la interculturalidad, alimentada por la teoría de la teología y la teoría de la política,

A pesar de estos avances, todavía subsisten factores que atentan contra este desarrollo humano equitativo y coartan la soberanía de los países de la "Patria Grande" y otras latitudes del planeta. El nuevo colonialismo adopta diversas fachadas. A veces, es el poder anónimo del ídolo 
dinero: corporaciones, prestamistas, algunos tratados denominados "de libre comercio" y la imposición de medidas de "austeridad" que siempre ajustan el cinturón de los trabajadores y los pobres. Los obispos latinoamericanos lo denunciamos con total claridad en el documento de Aparecida cuando se afirma que "las instituciones financieras y las empresas transnacionales se fortalecen al punto de subordinar las economías locales, sobre todo, debilitando a los Estados, que aparecen cada vez más impotentes para llevar adelante proyectos de desarrollo al servicio de sus poblaciones" (V Conferencia General del Episcopado Latinoamericano [2007], Documento Conclusivo, Aparecida, 66). En otras ocasiones, bajo el noble ropaje de la lucha contra la corrupción, el narcotráfico o el terrorismo - graves males de nuestros tiempos que requieren una acción internacional coordinada-, vemos que se impone a los Estados medidas que poco tienen que ver con la resolución de esas problemáticas y muchas veces empeoran las cosas (Francisco, 2017).

Únicamente de esta forma se hace efectivo desde la perspectiva encarnacional de Jesús, que "lo primero es el compromiso de caridad, de servicio. La teología viene después, es acto segundo" (Novoa, 2017, p. 1). Porque esta disciplina no engendra la acción, pero si tiene la posibilidad de establecer los mínimos parámetros de la defensa comprometida, que todo cristiano debe hacer de la dignidad humana.

En esta horizontalidad eclesial, será fundamental "salir de mi egoísmo hacia el otro para construir el bien de todos" (Novoa, 2017, p. 2), es decir, construir la alteridad, que obliga a que, si la personase tiene en cuenta, si no se trata de la globalización de la indiferencia, entonces la experiencia de fe cristiana para los creyentes estará presente en la economía, en la cultura y en la política. De tal manera que, la presencia del Espíritu del Resucitado en la comunidad de creyentes, sea

Para el beneficio de aquellos económica, física y socialmente desvalidos y excluídos. El Mesías no se predica a sí mismo, no viene a hacer gala egocéntrica de su individualidad como "uno de esos políticos corruptos y estafadores que tenemos" (Francisco, 2014, 1). Él viene a donarse en total gratuidad generosidad a todos, haciendo real el reinado de su Padre, Él es enviado "para que dé la buena noticia a los pobres" (Lc $4,18)$. Esta afirmación de Lucas no es una metáfora sobre las necesidades de Israel sino la constatación de que el favor de Dios está ejerciendo una restauración total (Novoa, 2017, p. 6). 
Esto pone de relieve la importancia de la dimensión comunitaria, política y ética (Novoa, 2016, p. 2) de la teología, sobre todo de una teología que sea de corte evangélico, fiel a la vivencia de las primeras comunidades y de la tradición. Una teología que viva su misión de salvación, y tenga la misericordia como centro del Evangelio de Jesús.

\section{Conclusión}

La teología y la política pueden entenderse como disciplinas sin comunicación aparente, cada una procede de una historia epistemológica propia; sin embargo, es importante demostrar que ellas en la historia se han intersectado en disputas, pero también en tónica de paz. De tal manera que, no se trata de disciplinas que se entrecruzan, sino que se constituyen mutuamente.

Es una cristiana quien redacta este escrito, desde la teología cristiana que ha sido protagonista en la historia de la humanidad. Se trata de una construcción que va tomando cada vez más fuerza en estas latitudes, la teología es inherentemente política. Y exige un comportamiento ético concreto con los congéneres con quienes realiza su proyecto de fe.

La teología política no solo es una disciplina, es un compromiso de todo creyente, es correlato de una encarnación que sea fielmente histórica, se trata de la vivencia plena del Evangelio. Pero sobre todo se trata más que de una opción epistemológica, de una opción del quehacer por lo existencial. Por lo relevante en contextos llenos de dolor y de sufrimiento.

Es la teología política el lugar del encuentro con la cultura, y no solo una cultura en términos antropológicos, sino una cultura en términos de modo de ser: la cultura de la dignidad para todos, en todas las geografías, en todas sus condiciones, en su fe o en su no creencia.

\section{Referencias}

Benedicto XVI. (2007). Mensaje de su santidad Benedicto XVI para la celebración de la XL Jornada Mundial de la Paz. La persona humana, corazón de la paz. Recuperado de: https://w2.vatican.va/content/benedict-xvi/es/messages/peace/ documents/hf_ben-xvi_mes_20061208_xl-world-day-peace.html

Bobbio, N. (1991). El tiempo de los derechos. Madrid, España: Sistema.

Boff, L. (2012). El cuidado necesario. Madrid, España: Trotta. 
De Sousa Santos, B. (2014). Si Dios fuese un activista de los derechos humanos. Madrid, España: Trotta.

Declaración de los Derechos del Hombre y del Ciudadano de 1789. Recuperado de: http://www.conseil-constitutionnel.fr/conseil-constitutionnel/root/bank_mm/ espagnol/es_ddhc.pdf

Francisco. (2013). Exhortación apostólica Evangelii Gaudium del santo padre Francisco a los obispos, a los presbíteros y diáconos, a las personas consagradas y a los fieles laicos sobre el anuncio del Evangelio en el mundo actual. Recuperado de: http://w2.vatican.va/content/francesco/es/apost_exhortations/documents/papafrancesco_esortazione-ap_20131124_evangelii-gaudium.html

Heidegger, M. (2014). Ser y tiempo, México: Fondo de Cultura Económica.

Juan Pablo II. (1987). Carta encíclica Sollicitudo Rei Socialis del sumo pontífice Juan Pablo II a los obispos, a los sacerdotes, a las familias religiosas, a los hijos e hijas de la Iglesia, así como a todos los hombres de buena voluntad al cumplirse el vigésimo aniversario de la Populorum Progressio. Recuperado de: http://w2.vatican.va/content/john-paul-ii/es/encyclicals/documents/hf_jpii_enc_30121987_sollicitudo-rei-socialis.html

Novoa M., C. (2016a). Cuestionamientos éticos a la paz. La alteridad en el debate ético contemporáneo. Pontificia Universidad Javeriana. Facultad de Teología, Bogotá D. C., Colombia.

- (2017b). ¿Favorece el TLC a las mayorías empobrecidas? Pontificia Universidad Javeriana, Facultad de Teología.

- (2016c). La alteridad en el debate ético contemporáneo, Pontificia Universidad Javeriana. Facultad de Teología, 2016, 3.

. (2017d). Método teológico liberador. Pontificia Universidad Javeriana, Facultad de Teología.

. (2017e). Todo actuar cristiano es político. Theologica Xaveriana, 158, 295-324.

. (2017f). Una propuesta de teología evangélica, Pontificia Universidad Javeriana, Facultad de Teología.

Obama, discurso en El Cairo (4 de junio de 2009). Revista de Prensa. Hemeroteca virtual. Recuperado de: https://www.almendron.com/tribuna/ discurso-de-obama-en-el-cairo/

ONU. (1948). Declaración Universal de los Derechos Humanos Personales y Sociales de 1948. Recuperado de: http://www.equidadmujer.gov.co/ejes/Documents/Normativa Nacional/Declaraci\%C3\%B3n\%20Universal\%20de\%20Derechos\%20 Humanos\%20de\%201948.pdf

UNESCO. (13 de abril de 2017). Organización de las Naciones Unidas para la Educación, la Ciencia y la Cultura. Recuperado de: http://www.unesco.org/new/ es/unesco/resources/publications/

Vigil, J. M. (1975). La política de la iglesia apolítica. Una aportación a la teología política desde la historia. Valencia, España: Edicep. 